\title{
Atendimento odontológico a pacientes com necessidades especiais: Considerações a respeito de um projeto de extensão
}

\author{
Lia Silva de Castilho ${ }^{1}$, Vera Lúcia Silva Resende², Ana Cláudia Pereira \\ Barros $^{3}$, Débora Carolina de Souza Lacerda 4 , Eduardo Emílio Maia \\ Marques $^{5}$, Natália de Frias Castro ${ }^{6}$, Amanda de Oliveira Pacheco $^{7}$
}

RESUMO: Este artigo descreve as experiências do projeto de extensão "Atendimento Odontológico ao Portador de Necessidades Especiais" da Faculdade de Odontologia da UFMG. As experiências em ensino, extensão e pesquisa apresentadas estão fortemente relacionadas entre si e com o objetivo geral da Associação Mineira de Reabilitação (AMR), instituição que abriga o referido projeto. Por isso, o resultado é muito positivo na formação do estudante de odontologia.

Palavras chave: Ensino, extensão universitária, odontologia.

Área temática: Saúde.

\footnotetext{
${ }^{1}$ Professoras do Departamento de Odontologia Restauradora da Faculdade de Odontologia da UFMG

${ }^{2}$ Professoras do Departamento de Odontologia Restauradora da Faculdade de Odontologia da UFMG

${ }^{3}$ Alunas do curso de Odontologia da Faculdade de Odontologia da UFMG, Bolsistas PBEXT

${ }^{4}$ Alunas do curso de Odontologia da Faculdade de Odontologia da UFMG, Bolsistas PBEXT

${ }^{5}$ Aluno do curso de Odontologia da Faculdade de Odontologia da UFMG

${ }^{6}$ Aluno do curso de Odontologia da Faculdade de Odontologia da UFMG

${ }^{7}$ Aluno do curso de Odontologia da Faculdade de Odontologia da UFMG
} 


\title{
Dental care to patients with special needs: Considerations of an extension project
}

\begin{abstract}
This article describes the experiences of the extension project "Dental treatment for special needs patients" from the Dental School of the Federal University of Minas Gerais (UFMG). The experiences on teaching, extension and research presented are strongly interrelated and connected with the general objective of the Associação Mineira de Reabilitação (AMR), institution that houses the mentioned project. Therefore, the result is very positive point in the formation of the dental student.
\end{abstract}

Keywords: Dentistry, teaching, university extension.

Thematic Area: Health.

\section{Cuidado dental para pacientes con necesidades especiales: Consideraciones de un proyecto de extensión}

RESUMEN: Este artículo describe las experiencias del proyecto de extensión "Cuidado Dental para portador de necesidades especiales" de la Facultad de Odontología de la UFMG. Las experiencias en docencia, investigación y extensión presentadas están fuertemente interrelacionados y con el objetivo general de la Asociación Minera de Rehabilitación (AMR), institución que alberga el mencionado proyecto. Por lo tanto, el resultado es muy positivo en la formación de estudiante dental.

Palabras clave: Educación, odontología, extensión universitaria.

Área temática: Salud. 


\section{INTRODUÇÃO}

O processo ensino-pesquisa-extensão possui papel preponderante na interação dialógica da universidade com a comunidade. A possibilidade de que o graduando possa experimentar essa integração em um cenário real, favorece a sua formação como um cidadão consciente e atuante, amplia sua percepção de mercado de trabalho e proporciona a inserção social da instituição de ensino. Essa inserção social da universidade se dá não só através da elaboração de soluções embasadas no conhecimento científico e no conhecimento popular (MOIMAZ et al., 2010, p.76), como também através de ações que promovam o desenvolvimento da consciência social e política do usuário e o bem-estar social da população. Em suma, o papel da universidade é propor soluções para os problemas prioritários da população e transformá-la em uma sociedade mais justa e solidária (ARAÚJO, 2006, p.180). Para alcançar tal intento, o ensino em odontologia deve promover uma prática onde a figura do cirurgião-dentista não seja o centro da ação. Nesta interação, a atuação do professor não pode ser encarada como arcabouço da verdade e como detentora de poder absoluto. Neste processo, é preciso convidar os alunos a se tornarem sujeitos no processo de ensino-aprendizagem, despertando o interesse pela busca do conhecimento. Além disso, é fundamental transcender a (ainda) resistente indiferença aos problemas comunitários e a preocupação com a incorporação de tecnologias que tornam sofisticados os procedimentos técnicos super-especializantes (LAZARIN et al., 2007, p.1804).

No processo pedagógico que norteia este projeto de extensão, tenta-se constantemente superar a fragmentação do ensino que está interligada à lógica do mercado e à profissionalização, evitando que estas estejam à frente em importância ao pensamento, à crítica e à criatividade. (LEMOS \& FONSECA, 2009, p.66).

A parceria da Universidade com o Sistema Único de Saúde, com certeza, é fundamental para o alcance destes resultados edificadores da sociedade (MOIMAZ et al., 2010, p.69). Entretanto, o trabalho com o terceiro setor apresenta-se como uma possibilidade de grande alcance para a resolução de problemas sociais que afetam o conjunto da população (JUNQUEIRA, 2004, p.27).

É sabido que estágios supervisionados em escolas, creches, asilos, hospitais, internatos em saúde coletiva ou internatos rurais, por si só não alcançam os objetivos das Diretrizes Curriculares Nacionais. Não é através de atividades curriculares pontuais que a universidade estabelece um compromisso social. Entretanto, quando o graduando pode experimentar uma série destes estágios ao longo do seu curso concatenados com a sua formação teórico-prá- 
tica intramuros, sua atuação se torna articulada às demandas dos serviços, sejam eles da esfera pública ou privada (FINKLER et al., 2011, p.1059). Por conseguinte, amplia-se a reflexão sobre a prática pedagógica em odontologia para um conceito sobre saúde mais abrangente, para as principais demandas de saúde bucal no país, para o desenvolvimento de uma abordagem em saúde mais integrada e multidisciplinar, transcendendo o simples aspecto técnico da profissão (LAZARIN et al., 2007, p.1808).

O trabalho em parceria entre a Universidade, serviços de saúde e organizações comunitárias é imprescindível para se formar um excelente profissional de saúde. Isto não ocorre somente pela natureza da profissão, mas pela necessidade de se conhecer a realidade para o desenvolvimento de uma consciência crítica. A prática cooperativa possibilita a emergência de novos temas e desafios ao ensino e à produção de conhecimento, reorientando o modelo assistencial. Assim, o ato de ensinar amplia-se metodológica e conceitualmente, transcendendo a perspectiva burocrática e elegendo a gestão democrática como missão (SILVA \& TAVARES, 2004, p.282).

Tendo por base o exposto, o presente trabalho apresenta a experiência do processo ensino-aprendizagem, iniciada em 1998, entre a Faculdade de Odontologia da Universidade Federal de Minas Gerais (FO-UFMG), a Associação Mineira de Reabilitação (AMR) e a Escola Estadual de Ensino Especial Dr. João Moreira Sales, no tratamento odontológico de pacientes com deficiências neuromotoras, através do Projeto de Extensão "Atendimento Odontológico a Pacientes Portadores de Necessidades Especiais".

\section{DESCRIÇÃO DAS ATIVIDADES DE EXTENSÃO}

\section{Histórico}

Este projeto de extensão iniciou em 1996, anteriormente ao convênio firmado entre as já citadas instituições. Neste ano, a FO-UFMG e a Prefeitura Municipal de Belo Horizonte (PBH), iniciaram um trabalho de mútua colaboração para tratamento odontológico ambulatorial e sob anestesia geral no Hospital da Baleia (Fundação Benjamin Guimarães). Neste período, cirurgiões-dentistas da $\mathrm{PBH}$ que se dispuseram a trabalhar com esta população foram treinados pelos professores da FO-UFMG. Paralelamente a este processo, graduandos da FO-UFMG participavam do atendimento e realizavam pesquisas exploratórias das diversas síndromes/deficiências dos seus pacientes e como produtos, vários trabalhos científicos foram realizados. No ano de 1998, um convênio entre a FO-UFMG e a AMR foi firmado com o objetivo de atender indivíduos portadores de deficiências neuromo- 
toras em tratamento no setor de reabilitação desta instituição, bem como alunos da Escola Estadual Dr. João Moreira Salles que funcionava em suas dependências (ABREU et al., 2001, p.154).

Tanto no Hospital da Baleia, quanto na AMR, 48\% dos pacientes que eram encaminhados para atendimento odontológico sob anestesia geral podiam ser atendidos na cadeira odontológica com algumas modificações na condução das técnicas restauradoras e de abordagem do paciente, sem comprometimento da qualidade do trabalho. Em 1999, o contrato entre a PBH e o Hospital da Baleia não foi renovado e o atendimento odontológico foi suspenso, restando o atendimento ambulatorial realizado nas dependências da clínica odontológica da AMR (ABREU et al., 2001, p.154). A AMR arca com os custos de infra-estrutura, material de consumo e de escritório e pessoal auxiliar. Além da UFMG, alunos dos cursos de fisioterapia, psicologia (graduação e pós-graduação) da Pontifícia Universidade Católica de Minas Gerais, de fisioterapia e terapia ocupacional da Universidade FUMEC, terapia ocupacional e musicoterapia da UFMG também participam de atividades extensionistas na instituição.

$\mathrm{O}$ atual contexto socioeconômico mundial necessita de maior eficácia na gestão das políticas públicas. Historicamente, as instituições públicas, responsáveis por este gerenciamento, muitas vezes não têm conseguido realizar essa tarefa em sua totalidade, por motivos diversos. Para a resolução deste impasse, novas alternativas são buscadas e, entre elas, o terceiro setor desponta. As organizações que constituem o terceiro setor são espaços institucionais que não se restringem a apenas um setor, mas são organizações que tornam palpável a realidade intersetorial. São cenários propícios ao desenvolvimento da cidadania (OLIVEIRA \& JUNQUEIRA, 2003, p.227). Essas organizações, em função do tempo e das suas trajetórias como realidades sociais, vão incorporando novos atores e novos interesses, independente da sua posição. A capacidade de intervenção e resolução dessas organizações das situações que afligem a sociedade depende diretamente das habilidades dos atores sociais que integram o processo de diagnóstico de problemas, como também da elaboração de novos conhecimentos organizacionais (JUNQUEIRA, 2004, p.26). Esta flexibilidade e agilidade de adaptação às novas e contínuas exigências sociais fazem do trabalho junto ao terceiro setor uma grande oportunidade de aprendizado para o graduando em odontologia.

A Faculdade de Odontologia da UFMG busca contribuir junto à AMR, através deste projeto, no planejamento de uma nova trajetória na qual a prática odontológica evolui de um modelo tecnológico assistencial hegemônico, fortemente centrado na execução de procedimentos para um modelo embasado pelas necessidades 
sociais da população assistida. Não há imposição de esquemas preconcebidos nem propostas de trabalho predefinidas. Aqui, tal como proposto por FINKLER et al. (2011, p.1065), as ações demandadas pelos usuários do setor de reabilitação são adequadas aos objetivos da formação do cirurgião-dentista.

\section{O TRABALHO EXTENSIONISTA}

O trabalho deste projeto se caracteriza pela sua essência multidisciplinar. As atividades realizadas integram um programa mais amplo da AMR, o Sistema Integrado de Reabilitação (SIR). Nele, os estudantes de odontologia da FO-UFMG têm contato com equipes de fisioterapia, fonoaudiologia, terapia ocupacional, serviço social, psicologia, educação física, ortopedia e neurologia no desenvolvimento do bem-estar do usuário da AMR com vistas à sua inclusão social. Em outra frente de trabalho, o graduando tem a oportunidade de trabalhar com profissionais da área de educação na ação conjunta com a Escola Estadual de Ensino Especial Dr. João Moreira Sales (VITTORINO et al., 2011, p.12). A meta é a inserção social do portador de deficiências neuromotoras e a odontologia contribui nesta trajetória norteada pela integralidade do cuidado.

Basicamente, o aluno recebe o seu paciente, estuda cada caso com as suas particularidades neurológicas e físicas e elabora um planejamento integral de tratamento odontológico (toda sua atuação é flexibilizada no currículo). Os casos que não possuem condições de serem resolvidos em ambulatório são encaminhados aos Postos de Saúde da PBH para serem redirigidos ao tratamento odontológico sob anestesia geral no Hospital Odilon Beherens.

Apesar de uma associação estatística não ter sido comprovada entre a presença de lesões de cárie e atendimento pela equipe multidisciplinar na AMR, acredita-se que o fato do paciente ser encaminhado pelos demais profissionais de saúde ao atendimento odontológico antes da instalação das lesões pode influenciar positivamente o excelente resultado apresentado pelo projeto no seu período de funcionamento (RESENDE et al., 2007, p.116; CASTILHO et al., 2012, p.148).

A importância da participação da odontologia no SIR é reconhecida pela equipe de profissionais envolvidos na reabilitação dos pacientes da AMR, tal como relatado anteriormente sobre a participação da equipe odontológica em ambiente hospitalar e seu relacionamento com os demais membros da equipe de saúde (MATEVI et al., 2011, p.4234). A interdisciplinaridade é um caminho para a correção das distorções provocadas pela super-especialização profissional e sua consequência mais direta: a fragmentação do conhecimento (ARAÚ- 
JO, 2006, p.181). De fato, este projeto contribui para desmistificar a visão de que o exercício profissional odontológico é caracteristicamente individual (EMERICH \& CASTIEL, 2009, p.340).

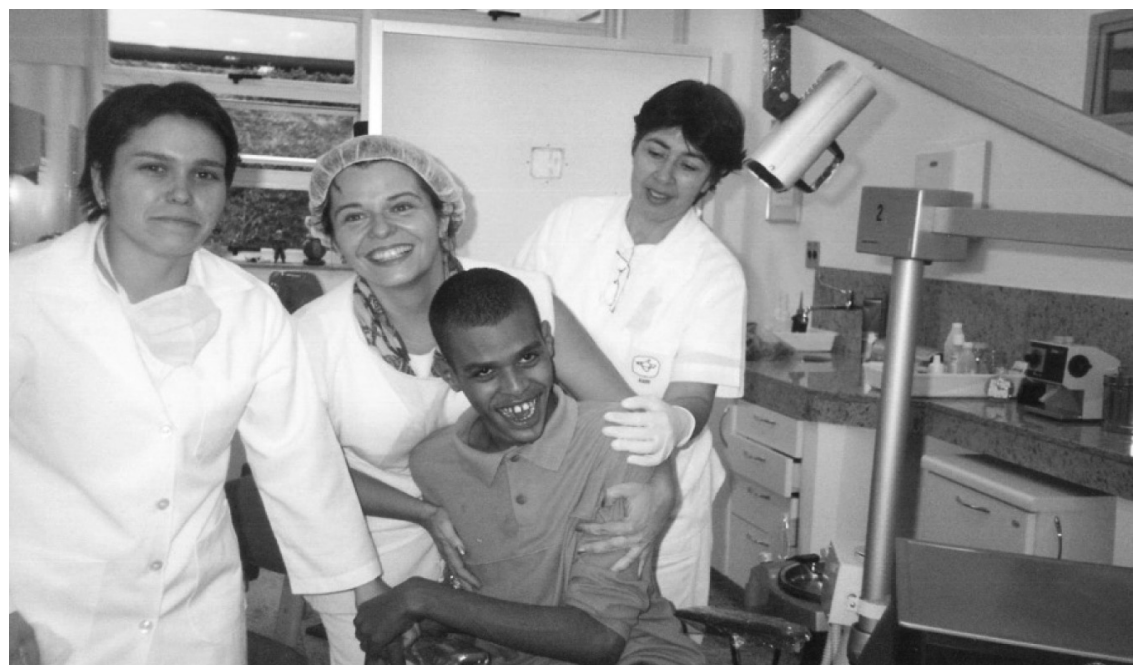

Figura 1- Atendimento Odontológico ao Portador de Necessidades Especiais, Faculdade de Odontologia da UFMG e Associação Mineira de Reabilitação

As bases conceituais para o atendimento individual neste projeto são aquelas próprias do modelo de atenção precoce (NICKEL et al., 2008, p.243). Como o trabalho com o paciente se inicia na primeira infância, o sucesso em manter indivíduos livres de cárie está em 67,4\% (RESENDE et al., 2007, p.114). Entretanto, muitas crianças já chegam ao consultório odontológico com lesões cariosas, muitas vezes tão extensas que já comprometem a polpa dentária. Dentre os indivíduos de 0 a 12 anos, oriundos da reabilitação, os agravos mais recorrentes se referem à cárie dentária. Já entre os indivíduos de maior idade, que vêm da Escola Estadual Dr. João Moreira Sales, a doença periodontal é mais frequente. Os procedimentos odontológicos cirúrgicos restauradores próprios da atenção primária são realizados e, posteriormente, o paciente entra em um programa de manutenção preventiva cujas sessões são espaçadas de acordo com a necessidade do indivíduo. Indivíduos com mais necessidades e uma soma maior de fatores predisponentes ao risco de cárie e de doença periodontal serão avaliados mais frequentemente pela equipe odontológica. Com isso pretende-se atingir o princípio de equidade.

Para Silva e Tavares (2004, p.276), o compromisso com o princípio da equidade pressupõe o emprego de critérios de discriminação positiva no processo de elaboração de políticas públicas. Alguns 
grupos populacionais ou alguns indivíduos são mais propensos a desenvolver doenças devido à sua condição socioeconômica e devem ser priorizados nos processos de intervenção estatal.

Além destas ações, busca-se a promoção da saúde bucal envolvendo estratégias de educação em saúde para pacientes, equipes de saúde, professores, pais e cuidadores. Estes procedimentos contribuem positivamente na saúde geral do portador de deficiências neuromotoras e, com isso, facilitam a sua inserção social (VITTORINO et al., 2011, p.13). Como propõe Silva e Tavares (2004, p.276), a integralidade da atenção prevê uma intervenção que atua sobre os indivíduos, as famílias, os ambientes coletivos, os grupos sociais e o meio ambiente.

Assumir a integralidade do cuidado como eixo de orientação na formação do cirurgião-dentista como dos demais profissionais de saúde lança luz sobre o conceito de omnilateralidade. Em outras palavras, de se levar em conta a totalidade na análise de qualquer fenômeno. Este processo requer um entendimento do mundo, da sociedade e das relações políticas de forma integral (SILVA \& TAVARES, 2004, p.280).

As práticas educativas em saúde são constantemente revisitadas no sentido de evoluir de um conceito fortemente positivista, ainda muito arraigado na academia, de ensino, instrução e prevenção de doenças que se baseia em orientações e informações diretamente passadas aos pacientes, professores, pais e responsáveis pelos alunos, sem considerar os saberes que estas pessoas trazem consigo. $\mathrm{O}$ que se espera é que a educação em saúde, dialógica e crítica, esteja voltada ao desenvolvimento da emancipação e da construção de mecanismos de controle social dos sujeitos e da comunidade para melhoria da qualidade de vida (MIALHE \& SILVA, 2011, p.1560). Não apenas o conhecimento científico é levado em conta para a adoção de hábitos saudáveis: pacientes, pais e responsáveis trazem consigo representações e conceitos que, ao serem trabalhados conjuntamente com o profissional de saúde, podem contribuir de maneira decisiva na modificação de hábitos deletérios.

As relações entre a Universidade e o mercado de trabalho devem superar o aprendizado formalista, baseado na simulação de situações de trabalho que não consideram a complexidade e a incerteza das situações concretas do processo saúde/adoecimento. Apenas inserir o graduando na prática não gera, por si, formação crítica e libertadora. Isto acontece quando se investiga quais os contextos formativos são capazes de gerar uma prática inovadora, crítica e reflexiva (SILVA \& TAVARES, 2004, p.281). 


\section{A FORMAÇÃo CIDADÃ DO ALUNO DE ODONTOLOGIA}

É consenso na Literatura que a preparação de estudantes para a atuação com portadores de necessidades especiais pressupõe a sensibilização e a predisposição ao contato com estes indivíduos, além, obviamente da formação técnica. Essa empatia inicial do aluno com o paciente influi diretamente na qualidade do cuidado, principalmente em relação ao princípio do acolhimento. Este princípio incorpora ações de escuta, orientação, atendimento, encaminhamento e acompanhamento. Este conjunto de ações caracteriza o primeiro ato de cuidado e contribui de forma incisiva para o aumento da resolutividade dos serviços e da adesão do usuário, além de contribuir na manutenção da saúde coletiva. A consequência mais evidente da sistematização dessas ações é a evolução de uma preocupação inicialmente beneficente para uma abordagem mais profissional do atendimento odontológico (MORAES et al., 2006, p.610).

Escutar atentamente o paciente ou os seus responsáveis leva-os a se sentirem compreendidos pelo profissional de saúde. Essa sensação de que as suas demandas fazem sentido àquele que escuta faz com que as avaliações dos serviços prestados sejam consideradas positivas (CAMILO \& MAIORINO, 2012, p.553). De fato, os alunos que possuem essa empatia, esse desejo de empregar os conhecimentos técnicos no tratamento de indivíduos com características especiais, procuram o projeto como voluntários (um semestre) e permanecem como bolsistas (bolsas PROEXT) por uma média de 18 meses. Esse laço de amizade, camaradagem e confiança desenvolvido entre paciente e terapeuta diminui a tensão causada pelo tratamento odontológico e é capaz de gerar soluções criativas para problemas rotineiros na clínica odontológica, tais como: uso de chupetas, consumo frequente de alimentos sacarosados, uso de mamadeira noturna, entre outros.

Em relação ao voluntariado, é preciso que o tema seja discutido, mesmo que rapidamente, à luz da maneira com que é tratado neste projeto. O trabalho do estudante, inicialmente, está intimamente relacionado com o desejo de aprender como abordar odontologicamente um paciente com deficiências neuromotoras. Em seguida, o trabalho voluntário passa pela necessidade de satisfação de preenchimento de lacunas existenciais que o Trabalho, sob o Capitalismo, deixa de abarcar. Desta forma, a ação voluntária permite ao estudante, que se envolve neste processo, completar diversos níveis de satisfação individuais. Finalmente, no processo em evolução, o aluno transcende as suas próprias necessidades subjetivas e ao se comprometer e ao dar voz aos ajudados pela ação voluntária come- 
ça a conceber e a resgatar o senso de comunidade perdido ao longo de processos históricos (CALDANA \& FIGUEIREDO, 2008, p.479).

Em um estudo sobre a percepção dos alunos de odontologia e a inclusão social de portadores de deficiências, os estudantes apresentavam uma concepção positiva sobre seus pacientes que foi aprimorada com a participação no módulo de Pacientes Especiais da disciplina de Psicologia Aplicada mostrando-se predispostos a ações inclusivas. As respostas que expressavam sentimentos de pena e receio na interação com este público diminuíram após as aulas e passaram a se associar à categoria "disposição para contato ou ação". Os autores ponderam que uma situação que se inicia com receio, passa para a etapa de busca de informações e culmina com a ação de interação social. Por parte da instituição formadora, a disponibilização de informações relevantes sobre o tema altera a maneira com a qual o estudante em odontologia encara o seu desafio. A execução técnica do procedimento odontológico é melhorada, mas também as disposições afetivas e os valores tornam-se positivos (MORAES et al., 2006, p.614).

O aluno, ao observar as diversidades sob uma nova ótica, acaba incorporando novos conteúdos, ideias e disposição para a ação. Desta forma, a atuação mais pró-ativa na atenção às necessidades do coletivo e na formação de habilidades e atitudes no graduando é resultado de associações construtivas de cada novo cenário e de cada nova situação (ANJOS et al., 2010, p.176)

Certos problemas inerentes ao processo ensino/aprendizagem que ocorrem especialmente em turmas maiores como falta de acesso, comportamentos de arrogância e intimidação por parte do docente e falta de compreensão de limites por parte dos discentes (CAVACA et al., 2010, p.316) não são observados neste projeto de extensão. Isto talvez ocorra porque as turmas são pequenas, porque os alunos possuem uma predisposição para este trabalho (são eles é que procuram o projeto) e porque os professores preocupam-se em atualizar em técnicas ativas de aprendizagem e aprofundar sobre os debates teóricos acerca de ensino/aprendizagem. De qualquer forma, neste projeto se vivencia uma relação erigida sobre a égide do respeito mútuo. Esta é uma característica fundamental para um ambiente onde possa ocorrer o exercício de uma prática humanizada, servindo de exemplo para a vida profissional do aluno em outros cenários de exercício da prática odontológica.

Aqui o graduando é estimulado pelo seu professor a canalizar sua predisposição em ações para a resolução dos problemas. Este ato exige um grau de confiança aluno-professor muito forte. Não é o professor que irá solucionar todas as questões, ele irá coordenar o 
processo, mas as repostas serão dadas pelo aluno. O objetivo final é formar profissionais que possuam habilidades de se comunicar com outros sujeitos (sejam eles usuários ou demais profissionais). CAVACA et al. (2010, p.314) ponderam que profissionais assim formados são mais flexíveis e possuem uma maior capacidade de adaptação a cenários nos quais uma decisão diagnóstica ou de tratamento deva ser compartilhada.

Neste projeto o aluno aprende fazendo. O total de horas de atividades teóricas é bem reduzido. A produção textual que embasa as atividades de atenção odontológica é disponibilizada previamente ao aluno. Tal como ponderado por Silva e Tavares (2004, p.279), esta é uma experiência de ensino baseada nos problemas que se apresentam. A experiência é uma categoria central. Conhecendo, compreende-se o mundo e pode-se agir cooperativamente baseado na solidariedade. Inicialmente, reflete-se a partir das vivências concretas prévias dos alunos. Esta forma de trabalho permite a ação interdisciplinar, abordando de forma integralizada, temas, conteúdos e ações. $\mathrm{O}$ aprendizado se dá por etapas, iniciando-se pela realidade e a ela retornando, transformando-a.

Pretende-se que este projeto de extensão contribua, mesmo que modestamente, na construção de uma experiência consistente, interdisciplinar e multiprofissional. Esta experiência pode ou não ser aproveitada no trabalho dentro do serviço público (como Estratégia de Saúde da Família, por exemplo). Como é uma prática que se relaciona intimamente com aquela realidade social e epidemiológica, voltada para a integralidade do cuidado, tal experiência é muito útil em qualquer área de atuação do profissional, seja ela privada, pública ou na esfera do terceiro setor.

De qualquer forma, seja no trabalho de promoção de saúde no Sistema Único de Saúde, seja na esfera privada, seja no trabalho junto ao terceiro setor, os cirurgiões-dentistas formados devem estar capacitados tecnicamente, psicologicamente e sob o ponto de vista político e humanístico. Sua formação deve ser crítica e libertadora, compromissada com a construção integral do ser, alargando suas possibilidades de escolha, entendimento, análise, pleno no exercício da cidadania e da solidariedade. Sem esta formação, o cirurgião-dentista não compreenderá a saúde como um produto social nem a complexidade de alcançá-la como meta a partir da escuta das demandas da população. Este novo profissional será capaz de contextualizar e solucionar os problemas de saúde da população, construir projetos sociais alternativos e exigir espaços sociopolíticos, garantindo o seu poder de decisão e mantendo a sua identidade cultural (SILVA \& TAVARES, 2004, p.272). 


\section{A PESQUISA}

No presente projeto de extensão procura-se ultrapassar as barreiras que separam formalmente o ensino da pesquisa, da distinção entre graduação e pós-graduação e da diferenciação entre formação básica e profissionalizante. Esta trajetória se dá em sentido contrário à fragmentação disciplinar, característica da especialização (MALTAGLIATI \& GOLDENBERG, 2011, p.446). Aqui a pesquisa faz parte da elaboração do planejamento integral do paciente e/ou de estratégias para desvendar os fatores de risco para esta população específica. Não existe a intenção de direcionar a formação do graduando para uma especialização em odontologia para pacientes especiais. A pesquisa neste contexto tem como objetivo a abordagem do paciente de forma integral. Ela interliga o que o aluno "apreendeu" em sua trajetória no processo educativo. Quando o estudante percebe que os procedimentos que faz na abordagem individual do paciente podem se somar e responder questões de saúde no patamar coletivo, suas ações passam a ter mais sentido.

Focado na diretriz de impacto e transformação e pela indissociabilidade da tríade ensino-pesquisa-transformação, este projeto busca construir um modelo preditivo de cárie dentária para a população alvo, através de constantes pesquisas (veiculadas através de artigos científicos, participações em congressos, defesa de dissertação e de monografias de especialização). Entre os trabalhos publicados, estudou-se o uso de índices que facilitam a detecção de grupos mais vulneráveis às doenças bucais (CASTILHO et al., 2000, p.195), o papel da escola (CASTILHO et al., 2002, p.B112), e da merenda escolar (CASTILHO et al., 2002, p.B112) na saúde bucal do portador de necessidades especiais, as principais causas de paralisia cerebral entre os participantes do projeto (CASTILHO et al., 2002, p.62), o papel da profissão e escolaridade maternas na saúde bucal destes pacientes (CASTILHO et al., 2002, p.63), o traumatismo dentário na bateria labial anterior diferenciando os indivíduos que caminham e os cadeirantes (SILVA et al., 2002, p.1), a influência da prematuridade ao nascer na cárie dentária (SILVA et al., 2002, p.84), o grau de independência para as atividades de vida diária e suas relações com a cárie dentária (CABRAL et al., 2003, p.42), relação entre o bruxismo e o uso de chupeta (MACEDO et al., 2006, p.1), influências da mamadeira (RESENDE et al., 2007, p.116), da higienização e do refluxo gastroesofágico no desenvolvimento da cárie dentária (ROBERTO et al., 2012, p.474). Há ainda uma série de descrição de casos clínicos sobre as síndromes de Möebius (SCARPELLI et al., 2008, p.319), Rubstein-Taybi (TELES et al., 2009, p.16) e Cornelia Lange (SCARPELLI et al., 2011, p.48). Estes trabalhos foram publicados nos Anais dos Congressos da Sociedade Brasileira de Pesquisas Odontológicas, Semana de Iniciação Científica 
da UFMG e vários Congressos de Extensão nacionais e internacionais. Os alunos da graduação têm ainda a oportunidade de trabalhar com pós-graduandos, desenvolvendo projetos de pesquisa de alta qualidade. No caso desta população específica, a mamadeira (RESENDE et al., 2007, p.116) e a inadequada higiene bucal (ROBERTO et al., 2012, p.474) são os principais fatores causadores da cárie dentária. O referido projeto gerou uma dissertação de mestrado e uma monografia de especialização, além de ser divulgado em programas de rádio, em jornais e em videoconferências dirigidas a profissionais da $\mathrm{PBH}$ e dos demais municípios do estado. Quando se analisa os trabalhos em que são citados, percebe-se que a experiência do projeto é possível de ser aproveitada no desenvolvimento de programas odontológicos para indivíduos especiais e também para outros grupos como os índios Xacriabá (DUMOND et al., 2008, p.1019).

Os trabalhos publicados dividem-se em estudos epidemiológicos, relatos de casos clínicos e análise crítica das atividades do projeto (CASTILHO et al., 2012, p.149). Estes últimos são fundamentais para a construção do conhecimento humano e ajudam aquele profissional que recebe um caso isolado para tratamento. Por outro lado, o trabalho com a população de pacientes já atendidos envolve conhecimentos de epidemiologia e bioestatística aplicados à população específica. Estes conhecimentos embasam o conjunto de ações importantes para o reconhecimento da estrutura do serviço e de relevância na formação direcionada aos serviços de saúde (SOUZA \& CARCERERI, 2011, p.1076). Além disso, encontra-se em fase de elaboração um projeto de pesquisa que busca investigar o impacto deste projeto de extensão na promoção de saúde entre os pacientes atendidos tanto ambulatorialmente quanto através das atividades coletivas de promoção de saúde.

As realizações deste projeto apresentam em seu arcabouço a característica de projetarem valores sociais relevantes em associação com resultados com a finalidade de impactar as qualidades de formação do estudante de odontologia e de vida dos portadores de deficiências neuromotoras. Como sublinha Cabral (2011, p.1916), o conceito de gestão social, como reprodutora de valores e produtora de bens públicos objetivando alcançar uma meta, propõe uma avaliação que considere os elos entre os valores e os benefícios com a finalidade de medir o impacto social dos projetos. Aliado ao conceito de espaço público, este vínculo permite tratar as questões da intangibilidade dos benefícios, do tamanho dos projetos e da imitação de métodos adaptados que são insuficientes para perceber os valores sociais relevantes. Essa aproximação entende o conceito de espaço público (no caso o setor de Reabilitação da AMR e o SIR) como central e explicita os benefícios dos projetos sociais por envolverem respostas detectáveis na mo- 
dalidade de bens públicos e valores sociais reproduzidos na gestão. Com este reconhecimento, o foco é direcionado à construção de um referencial normativo para a concepção e explicitação do conteúdo informativo da avaliação, partindo do ponto de vista dos significados dos valores que motivaram os indivíduos a se juntarem para alcançar determinados objetivos (incluindo o estudante de odontologia) e dialoga com a gestão social embasada nestes significados. A especificidade dos benefícios embasados em valores e resultados é um desafio ao desenvolvimento de uma cultura de avaliação que abarque metodologias tanto dos serviços públicos quando dos serviços privados. É preciso que esta metodologia avaliativa investigue mudanças objetivas, como mudança na qualidade de vida dos usuários e do aluno de odontologia, como também de valores que embasem a construção da representação social dessa qualidade de vida tida como desejável.

Para explicitar graficamente este conjunto de fatos e valores e como eles se rearranjam em função da missão da AMR, elaborou-se a partir do proposto por Cabral (2011, p.1930). Nele, recursos, atividades, bens públicos, resultados e mudanças se concatenam em função do benefício gerado que é o impacto mensurado pela variação dos indicadores (Figura 2). O bem público foi entendido como os produtos concretos que serão desfrutados pelo público (graduação em odontologia e pacientes do projeto). Em "resultados" tem-se os resultados decorrentes da fruição do bem público e a transmissão de valores consequente.

Percebe-se, pois, que o presente projeto de extensão é um espaço para experiências problematizadoras com participação ativa do graduando. De fato, a extensão deve ser um objetivo básico do ensino superior e deve ser vislumbrada como necessariamente multidisciplinar, buscando a transdiciplinariedade. Isso é traduzido na ação conjunta da universidade com a população para resolução dos problemas. A pesquisa deve diagnosticar e propor soluções para os problemas de maneira ampliada de uma maneira intersetorial. $\mathrm{O}$ ensino superior deve instrumentalizar docentes, discentes e grupos representativos da comunidade para debater as questões que mais afligem a população e com isso, buscar as soluções a curto, médio e longo prazo (ARAÚJO, 2006, p.180). Por isso, é imprescindível na formação de um profissional crítico e reflexivo, a busca por novas experiências pedagógicas que promovam a autonomia intelectual do estudante e que desenvolvam a sua criatividade (MALTAGLIATI \& GOLDENBERG, 2011, p.437). Além disso, a experiência permite que a Faculdade de Odontologia cumpra o seu papel de produção do conhecimento científico e de inovação tecnológica que facilitem a vida destes pacientes. De fato, como salienta Anjos et al. (2010, p.181) a universidade, a partir destas experiências em cenários extramuros, 
contribui propondo novas metodologias mais cuidadosas, integralizáveis, com vínculos de responsabilização e resolubilidade colaborando com a construção de um sistema de saúde mais ativo, justo e ético.

\begin{tabular}{|c|c|c|c|c|}
\hline $\begin{array}{l}\text { Recursos } \\
\text { (necessidades) }\end{array}$ & Atividades & Bens Públicos & Resultados & Benefício \\
\hline $\begin{array}{l}\text { Consultório } \\
\text { odontológico } \\
\text { (construção) }\end{array}$ & $\begin{array}{l}\text { Educação em } \\
\text { saúde bucal }\end{array}$ & $\begin{array}{l}\text { Treinamento de } \\
\text { recursos humanos }\end{array}$ & $\begin{array}{l}\text { Pacientes livres } \\
\text { de cárie }(65 \%)\end{array}$ & $\begin{array}{l}\text { Contribuição } \\
\text { para inserção } \\
\text { social do } \\
\text { portador de } \\
\text { deficiências }\end{array}$ \\
\hline $\begin{array}{l}\text { Equipamentos } \\
\text { odontológicos } \\
\text { (aquisição) }\end{array}$ & $\begin{array}{l}\text { Atividades para } \\
\text { controle de lesões } \\
\text { incipientes de } \\
\text { cárie dentária }\end{array}$ & $\begin{array}{l}\text { Desenvolvimento } \\
\text { da autoestima } \\
\text { e envolvimento } \\
\text { familiar }\end{array}$ & $\begin{array}{l}\text { Controle } \\
\text { da doença e } \\
\text { manutenção da } \\
\text { saúde }\end{array}$ & \\
\hline $\begin{array}{l}\text { Material } \\
\text { odontológico }\end{array}$ & $\begin{array}{l}\text { Atividades } \\
\text { para controle } \\
\text { da gengivite, } \\
\text { cálculo e doença } \\
\text { periodontal }\end{array}$ & $\begin{array}{l}\text { Desenvolvimento } \\
\text { no graduando } \\
\text { em odontologia } \\
\text { do sentimento } \\
\text { de empatia pelo } \\
\text { paciente }\end{array}$ & $\begin{array}{l}\text { Controle } \\
\text { de hábitos } \\
\text { deletérios }\end{array}$ & \\
\hline $\begin{array}{l}\text { Auxiliar de } \\
\text { Consultório } \\
\text { Dentário }\end{array}$ & $\begin{array}{l}\text { Atividades } \\
\text { cirúrgico- } \\
\text { restauradoras }\end{array}$ & $\begin{array}{l}\text { Desenvolvimento } \\
\text { do interesse pela } \\
\text { pesquisa e pela } \\
\text { participação em } \\
\text { reuniões de cunho } \\
\text { científico }\end{array}$ & $\begin{array}{l}\text { O aluno é } \\
\text { responsável pelo } \\
\text { seu paciente e } \\
\text { pelo coletivo de } \\
\text { pacientes }\end{array}$ & \\
\hline $\begin{array}{l}\text { Alunos do curso } \\
\text { de odontologia }\end{array}$ & $\begin{array}{l}\text { Atividades de } \\
\text { promoção integral } \\
\text { da saúde }\end{array}$ & $\begin{array}{l}\text { Difusão do } \\
\text { conhecimento } \\
\text { científico } \\
\text { produzido }\end{array}$ & $\begin{array}{l}15 \text { Artigos } \\
\text { científicos e } 30 \\
\text { participações em } \\
\text { congressos }\end{array}$ & \\
\hline $\begin{array}{l}\text { Professoras } \\
\text { do curso de } \\
\text { odontologia }\end{array}$ & $\begin{array}{l}\text { Atividades lúdicas } \\
\text { de adaptação } \\
\text { comportamental }\end{array}$ & $\begin{array}{l}\text { Estímulo ao } \\
\text { trabalho voluntário }\end{array}$ & $\begin{array}{l}\text { Dissertação de } \\
\text { mestrado }\end{array}$ & \\
\hline $\begin{array}{l}\text { Custos diretos } \\
\text { (água, luz, } \\
\text { telefone, entre } \\
\text { outros) }\end{array}$ & $\begin{array}{l}\text { Ensino em } \\
\text { odontologia }\end{array}$ & $\begin{array}{l}\text { Envolvimento } \\
\text { familiar como } \\
\text { co-participe da } \\
\text { promoção de saúde } \\
\text { do paciente e da } \\
\text { própria família }\end{array}$ & $\begin{array}{l}\text { Monografia de } \\
\text { especialização }\end{array}$ & \\
\hline $\begin{array}{l}\text { Material de } \\
\text { limpeza e de } \\
\text { escritório }\end{array}$ & $\begin{array}{l}\text { Produção de } \\
\text { conhecimento } \\
\text { científico }\end{array}$ & $\begin{array}{l}\text { Adoção de hábitos } \\
\text { saudáveis }\end{array}$ & $\begin{array}{l}\text { Monografia } \\
\text { de iniciação } \\
\text { científica }\end{array}$ & \\
\hline Custos sociais & Temas sociais & Fatos e valores & Indicadores & Impacto \\
\hline
\end{tabular}

Figura 2 - Mapa de Bens públicos Faculdade de Odontologia, AMR e E.E. João Moreira Salles- Fatos e valores (adaptado de CABRAL, 2011: 1930)

Uma experiência que contemple práticas ativas de ensino concatenando a atenção em saúde, a gestão do serviço e o controle social com a defesa do interesse público não é como pondera FINKLER et 
al. (2011, p.1065) uma tarefa fácil. Esta é a trajetória que precisa ser trilhada através da ação intersetorial na saúde e na educação, despertando a sensibilidade, concebendo a reflexão e o diálogo, negociando e superando os problemas apresentados pela população, com vistas à construção da cidadania e da democracia.

\section{CONSIDERAÇÕES FINAIS}

É uma tarefa difícil avaliar criticamente um projeto de extensão que já dura tanto tempo. Entretanto, essa mesma durabilidade pode informar, mesmo que indiretamente, que instituição de ensino, instituição parceira, usuários, profissionais de saúde e alunos estejam satisfeitos com a sua existência. O resultado de $67,4 \%$ de pacientes livres de cárie é o indicador mais objetivo do seu sucesso. Este projeto proporciona ao graduando de odontologia um novo cenário de práticas no qual o trabalho multidisciplinar é uma realidade dentro de um modelo de instituição diferente daquele onde ele está acostumado a trabalhar. A busca da inserção social do portador de deficiências deixa de ser uma meta distante para se tornar uma realidade graças a este trabalho em conjunto. A produção científica deste projeto, por outro lado, é a sua contribuição mais ampla. A participação ativa dos alunos nesta produção é um sinalizador da capacidade de construção do conhecimento e de inovação deste empreendimento. Pois quando as experiências (positivas ou não) são compartilhadas, iniciativas inclusivas surgem em vários locais, aquelas que já existem se fortalecem e a promoção social se efetiva. É esse o papel da Universidade.

\section{REFERENCIAS BIBLIOGRÁFICAS}

ABREU, M.H.N.G.; CASTILHO, L.S.; RESENDE, V.L.S. Assistência odontológica a indivíduos portadores de deficiências: o caso da Associação Mineira de Reabilitação e Escola Estadual "João Moreira Salles". Arquivos em Odontologia, v.37, n.2, p.153-162, 2001.

ABREU, M.H.N.G. et al. Mechanical and chemical home plaque control: a study of Brazilian children and adolescents with disabilities. Special Care Dentistry, v.22, p.59-64, 2002.

ANJOS, R.M.P.; GIANINI, R.J.; MINARI, F.C.; LUCA, A.H.S.; RODRIGUES, M.P. "Vivendo o SUS": uma experiência prática no cenário da atenção básica. Revista Brasileira de Educação Médica, v.34, n.1, p.172-183, 2010.

ARAÚJO, M.E. Palavras e silêncios na educação superior em odontologia. Ciência \& Saúde Coletiva, v.11, n.1, p.179-182, 2006.

CABRAL, J.C.M.; CASTILHO, L.S.; RESENDE, V.L.S. Determinantes sociais e comportamentais de doença bucal em crianças portadores de necessidades especiais. Pesquisa Odontológica Brasileira, v.17, p.42, 2003. 
CABRAL, E.H.S. Valores e espaço público: referenciais e instrumentos para a avaliação de projetos sociais. RAP - Rio de Janeiro, v.45, n.6, p.1915-41, nov./dez. 2011.

CALDANA, A.C.F.; FIGUEIREDO, M.A.C. O voluntariado em questão: A subjetividade permitida. Psicologia, Ciência e Profissão, v.28, n.3, p.466-479, 2008.

CAMILLO, S.O.; MAIORINO, F.T. A importância da escuta no cuidado de enfermagem. Cogitare, v.17, n.3, p.549-555, 2012.

CASTILHO, L.S. et al. Utilização do INTO para triagem de grandes grupos populacionais. Revista do Conselho Regional de Odontologia de MG., v.6, p.195-199, 2000.

CASTILHO, L.S.; RUAS, R.O.; RESENDE, V.L.S. The role of the school in the bucal health in patients with disability. Journal of Dental Research, v.81, p.B112, 2002.

CASTILHO, L.S; RESENDE, V.L.S.; MARINHO K.C. Analysis of the diet in patients with neuropsicomotor deficiencies. Journal of Dental Research, v.81, p.B112, 2002.

CASTILHO, L.S.; RESENDE, V.L.S.; APOLONIO, A.C.M. Principais causas de deficiências neuropsicomotoras X promoção de saúde. Arquivos em Odontologia, v.38, p.62, 2002.

CASTILHO, L.S.; RESENDE, V.L.S.; CABRAL, J.C.M. Profissão e escolaridade maternas x saúde bucal do paciente especial. Arquivos em Odontologia, v.38, p.63, 2002.

CASTILHO, L.S.; BARROS, A.P.; SOUZA, G.L.N. et al. A contribuição da odontologia na equipe multidisciplinar na promoção de saúde do paciente com paralisia cerebral. Revista de Extensão, v.2, p.141-153, 2012.

CAVACA, A.G. A relação professor-aluno no ensino da odontologia na universidade federal do espírito santo. Trab. Educ. Saúde, v.8, n.2, p.305-318, 2010.

DUMOND, A.F.S. et al. Índice de necessidade de tratamento odontológico: o caso dos índios Xacriabá. Ciência \& Saúde Coletiva, v.13, n.3, p.1017-1022, 2008.

EMERICH, A.; CASTILE, L.D. A ciência odontológica, sísifo e o "Efeito Camaleão". Interface, v.13, n.29, p.339-351, 2009.

FINKLER, M. et al. Integração "ensino-serviço" no processo de mudança na formação profissional em Odontologia. Interface Comunicação, Saúde, Educação, v.15, n.39, p.1053-67, 2011.

JUNQUEIRA, L.A.P. A gestão intersetorial das políticas sociais e o terceiro setor. Saúde e Sociedade, v.13, n.1, p.25-36, 2004.

LAZARIN, H.C. et al. Percepção de professores de odontologia 1-no processo de ensino-aprendizagem. Ciência e Saúde Coletiva, v.15 (Supl1), p.1810, 2010.

LEMOS, C.L.S.; FONSECA, S.G. Conhecimento e práticas curriculares: uma análise de um curso superior na área de saúde. Interface Comunicação, Saúde, Educação, v.13, p.57-69, 2009.

MACEDO, W.S. et al. Cárie, bruxismo, tipo de respiração e suas relações com gênero, idade e uso de chupeta em pacientes especiais. Anais da XV Semana de Iniciação Científica da UFMG, 2006.

MALTAGLIATI, L.A.; GOLDENBERG, P. O lugar da pesquisa na reorganização curricular em odontologia: desafios de origem para um debate atual. Saúde e Sociedade, v.20, n.2, p.436-447, 2011. 
MATEVI, G.S. A participação do cirurgião-dentista em equipe de saúde multidisciplinar na atenção à saúde da criança no contexto hospitalar. Ciência \& Saúde Coletiva, v.16, n.10, p.4229-4236, 2011.

MIALHE, F.L.; SILVA, C.M.C. A educação em saúde e suas representações entre alunos de um curso de odontologia. Ciência \& Saúde Coletiva, v.16 (Supl 1), p.1555-1561, 2011.

MOIMAZ, A.S.S. et al. Práticas de ensino-aprendizagem com base em cenários reais. Interface Comunicação, Saúde, Educação, v.14, n.32, p.69-79, 2010.

MORAES, A.B.A. et al. Verbalizações de alunos de odontologia sobre a inclusão social de pessoas com deficiência. Psicologia em Estudo, v.11, n.3, p.607-615, 2006.

NICKEL, D.A. et al. Modelos assistenciais em saúde bucal no Brasil. Caderno Saúde Pública, v.24, n.2, p.241-246, 2008.

OLIVEIRA, W.F.; JUNQUEIRA, L.A.P. Questões estratégicas na reforma sanitária: desenvolvimento do terceiro setor. Revista de Administração Pública, v.37, n.2, p.227-242, 2003.

RESENDE, V.L.S.; CASTILHO, L.S.; VIEGAS, C.M.S. et al. Fatores de risco para a cárie em dentes decíduos de portadores de necessidades especiais. Pesq. Bras. Odontoped. Clin. Integr., v.7, p.111-117, 2007.

ROBERTO, L.L.; MACHADO, M.G.; RESENDE, V.L.S. et al. Factors associated with dental caries in the primary dentition of children with cerebral palsy. Braz. Oral Res., v.26, n.5, p.471-477, 2012.

SCARPELLI, A.C. et al. Cornelia de lange syndrome: A case report of a Brazilian boy. The Cleft Palate-Cranio Facial Journal, p.48 (on line), 2011.

SCARPELLI, A.C. et al. Moebius syndrome: a case with oral involvement. The Cleft Palate-Cranio Facial Journal, v.45,p.319-324, 2008.

SILVA, C.P.E.; CABRAL, J.C.M.; CASTILHO, L.S. et al. Traumatismo dental anterior em portadores de deficiências neuropsicomotoras. Resumos da XI Semana de Iniciação Científica da UFMG. Belo Horizonte: UFMG, 2002.

SILVA, C.P.E.; SANS, F.M.M.; CASTILHO, L.S. et al. Cárie dentária em pacientes especiais: influências da idade, prematuridade e escolaridade materna. Pesquisa Odontológica Brasileira, v.17, p.84-84, 2003.

SILVA, J.P.; TAVARES, C. Integralidade: dispositivo para a formação crítica de profissionais de saúde. Trabalho, Educação e Saúde, v.2 n.2, p.271-285, 2004.

SOUZA, A.L.; CARCERERI, D.L. Estudo qualitativo da integração ensino-serviço em um curso de graduação em Odontologia. Interface Comunicação, Saúde, Educação, v.15, n.39, p.1071-1084, 2011.

TELES, C.G.; ALMEIDA, C.E.F.; CASTILHO, L.S. et al. Síndrome de Rubinstein-Taybi: revisão da literatura e descrição de conduta odontológica. Revista do CROMG, v.10, p.16-21, 2009.

VITTORINO, G.G.; SOUZA, G.G.; SILVA, H.M. et al. Atendimento odontológico a pacientes com necessidades especiais: treze anos promovendo sorrisos. Arq Odontol., v.47(Supl 2), p.12-15, 2011. 